\title{
Un boedismo optimista. El realismo socialista en Argentina a la luz de un concurso de cuentos de la revista Cuadernos de Cultura
}

\author{
An "optimistic boedismo". The socialist realism in Argentina in light of a \\ story's tender of the Cuadernos de Cultura magazine
}

\author{
María Fernanda Alle*
}

\begin{abstract}
Resumen: Este artículo indaga el programa literario que formula y promueve la revista Cuadernos de Cultura en el marco de la recepción de la doctrina cultural codificada por Andréi Zhdanov en los años de la segunda posguerra. A la luz de los cuentos ganadores del concurso que organiza la revista en 1954, se sostiene que ese programa literario puede definirse como un "boedismo optimista", en la medida en que recupera una mirada de la pobreza filiada con el miserabilismo boedista para ponerla en función del "desarrollo revolucionario" que pautaba el realismo socialista.
\end{abstract}

Palabras clave: Cuadernos de Cultura, Realismo socialista, Boedismo optimista, Concurso de cuentos

\begin{abstract}
This article investigates the Cuadernos de Cultura's literary program time frame of the receipt of the cultural doctrine codified by Andréi Zhdanov, in light of the winner stories of the tender organized by the magazine in 1954. It's argued that the literary program that promotes the magazine can be defined as an "optimistic boedismo", in that it recovers a glance of the poverty affiliated with the "miserabilismo boedista" to put it in function of the "revolutionary development" that guided the doctrine of the socialist realism.
\end{abstract}

Keywords: Cuadernos de Cultura, Socialist realism, Optimistic Boedismo, Story's tender

Recibido: 05/06/2017

Aceptado: 06/08/2017

\footnotetext{
* Argentina. Doctora en Humanidades y Artes, mención Literatura por la Universidad Nacional de Rosario. Becaria Postdoctoral del Consejo Nacional de Investigaciones Científicas y Técnicas (2017-2019). Lugar de trabajo: CEDINTEL, Universidad Nacional del Litoral. Docente de la cátedra "Análisis y Crítica I", de la carrera de Letras de la Universidad Nacional de Rosario. Correo electrónico: mariafernandaalle@ gmail.com
} 


\section{Notas iniciales}

En su número 19, de diciembre de 1954, la revista Cuadernos de Cultura, el principal órgano de difusión cultural del Partido Comunista Argentino a lo largo de las décadas del 50 y 60, publica, en una sección especial, los cuatro cuentos ganadores de un concurso que venía difundiendo desde mediados de ese año. El primero y el segundo de esos cuentos, titulados respectivamente "El hombre de los zapatos amarillos" y "Una mañana cualquiera", recibieron el primer premio y pertenecen a Alberto Foradori, un colaborador frecuente de la sección "Notas sobre cine" de la revista; el tercero, "Los Funes", corresponde al segundo puesto y su autor es Pedro Herbstein; el último, del rosarino Aisik Liúbaro, se titula “¡Soñador, feliz soñador!” y obtuvo el tercer lugar.

Si bien la revista ha sido objeto de estudio por parte de la historiografía, cabe señalar que hasta ahora no se ha atendido a estos cuentos ni al hecho mismo de que la revista llamara a un concurso literario. En esta dirección, aunque la calidad literaria de los cuentos sea ciertamente discutible, su recuperación para el análisis de los debates literarios que se suscitan en Cuadernos contribuye a echar luz sobre los ejes de discusión en torno de los cuales la revista fue pensando y ensayando las posibilidades de un programa literario nacional y, además, sobre la actividad de promoción que lleva a cabo para estimular la creación según ese programa. $\mathrm{O}$, dicho de otro modo, los cuentos permiten revisitar los parámetros axiológicos explicitados en las reseñas, notas y comentarios literarios de la revista desde una nueva perspectiva, capaz de iluminar los modos en que ese programa encontró formas de concreción en la práctica creativa.

Las bases y condiciones del concurso habían sido publicadas en la contratapa del número 16, de junio de ese año, donde también se dieron a conocer los nombres del jurado, integrado por algunos de los más prestigiosos escritores e intelectuales comunistas: Héctor Agosti, Raúl González Tuñón, Raúl Larra, Luis Gudiño Kramer y Gerardo Pisarello. Sin embargo, tal como se señala en la nota introductoria a los cuentos, Agosti no pudo finalmente tomar parte de las decisiones, comunicadas en una reunión realizada el día 3 de septiembre en Rosario, porque se encontraba detenido desde el 14 de julio de ese año en la cárcel de Villa Devoto, de donde saldrá recién luego del derrocamiento de Perón.

Además de las precisiones en cuanto a la extensión y el formato -el cuento no podía exceder las cinco mil palabras y debía presentarse escrito a máquina en una sola carilla- y otros requisitos usuales de cualquier concurso - como el uso de seudónimo, por ejemplo-, en la contratapa del número de junio, se detallaba que "El tema de los cuentos es libre, aunque deberá referirse a un asunto de índole nacional". Esa indicación, sumada a la declaración del equipo editorial, en la introducción a los cuentos del número 19, de "haber contribuido, con este concurso, a revelar las posibilidades de una literatura realista en la Argentina", ${ }^{1}$ brindan dos claves precisas para anclar el programa literario que se formula y se difunde desde las páginas de la revista. Realismo y temática nacional son, en efecto, los

1 “Los cuentos premiados”, Cuadernos de Cultura n 19, diciembre de 1954, 136. 
rasgos sobresalientes que se desprenden tanto de esos textos declarativos que rodean al concurso como de las mismas tramas narrativas de los cuentos ganadores y que, más ampliamente, constituyen los cimientos en torno de los cuales se organiza el programa literario comunista en la Argentina de la década del 50.

En líneas generales, podría decirse que los relatos ganadores adscriben a una estética realista, de cuño boedista, cuyo interés es poner en escena problemas que, desde la perspectiva partidaria, aquejan al pueblo argentino. Los rasgos boedistas de esos cuentos pueden rastrarse, por un lado, en la representación de personajes trabajadores -obreros, changarines, peones rurales, inmigrantes-, de humilde extracción social, que deben enfrentarse a situaciones frustrantes, humillantes e injustas que afectan su vida laboral y familiar; y, por otro, de la construcción de ambientes en los que domina la pobreza material, pero no siempre, como veremos, moral. Ahora bien, si los cuatro cuentos ficcionalizan conflictos y situaciones de índole "nacional" que, siguiendo el modelo de Boedo, parecen no ofrecer salida, sus desenlaces, como veremos, frustran esta primera expectativa.

En las próximas páginas buscaré, en primer lugar, circunscribir la preocupación por el realismo y lo nacional de los comunistas argentinos en el horizonte de la recepción de la doctrina del realismo socialista codificada por Andréi Zhdanov en la segunda posguerra ante la agenda de problemas impuesta por el peronismo. En un segundo momento, centraré la atención en los ejes principales en torno de los cuales se va elaborando el programa literario comunista desde las páginas de la revista Cuadernos de Cultura, para volver, finalmente, sobre los cuentos ganadores del concurso literario, a fin de revisar cómo se ponen en juego esos ejes del programa en la escritura creativa. La hipótesis que orienta el desarrollo de estas páginas es que el interés por construir una tradición literaria nacional, en términos realistas, deriva en un programa que recupera la herencia de Boedo para "completarla" con la incorporación del "elemento revolucionario" que le faltaba al primero y que constituye una de las exigencias del realismo socialista. El programa comunista de los años 50 se nos irá develando, así, como un "boedismo optimista". Pero, además, el hecho mismo de que la revista convocara a un concurso literario hace evidente que su proyecto rebasaba el objetivo de ser un "órgano de estudio y discusión", tal como se explicitaba en la nota editorial del número 7 -el primero bajo la dirección de Héctor Agosti-, para concentrarse además en impulsar y estimular la creación literaria según los ejes pautados por el programa que se va esbozando en sus páginas.

\section{El zhdanovismo cultural en Argentina}

En los años de la Guerra Fría, la doctrina del realismo socialista -que venía rigiendo los destinos del arte soviético desde que el Primer Congreso de Escritores realizado en Moscú, en 1934, la impusiera como estética "oficial”- adquirió, con Andréi Zhdanov al frente del control cultural, un renovado y sostenido impulso. Si, tal como sostiene Solomon Volkov, durante el período de la ocupación alemana (1941-1943) se produjo una "relajación del 
yugo ideológico" que redundaría en "condiciones más liberales en el conjunto de la cultura soviética", 2 el enfrentamiento entre las dos grandes potencias surgidas de la segunda guerra, ${ }^{3}$ se va a traducir en el ámbito de la literatura en un fortalecimiento del contenido anti-capitalista del realismo socialista, que se asociará a una renovación, de intensidad inédita, de la vigilancia y el control sobre la producción artística y, de manera concomitante, de la censura. ${ }^{4}$

Si bien, como señala Eric Hobsbawm, el período de la Guerra Fría no constituye un período "homogéneo", lo cierto es que, en su conjunto, ese bloque temporal siguió "un patrón único marcado por la peculiar situación internacional que lo dominó", cuya clave fue "el enfrentamiento constante de las dos superpotencias surgidas de la segunda guerra mundial": la Unión Soviética y los Estados Unidos. Durante este período, será entonces el imperialismo norteamericano el principal enemigo internacional ante el cual el Partido Comunista defina sus programas de acción.

Tal como explica Adriana Petra, en septiembre de 1947, en una reunión secreta que se llevó a cabo en Polonia, "los soviéticos oficializaron al mundo, por la voz de su delegado Andrei Zhdanov, la ruptura de la gran alianza nacida de la guerra” $y$, con ella, la división del mundo en dos grandes bloques: "de un lado, el campo imperialista y antidemocrático, dominado por los Estados Unidos; del otro, el campo antiimperialista, democrático y defensor de la paz, hegemonizado por la URSS". De acuerdo a ese diagnóstico, sostiene Petra, "la tarea principal" a la que se abocará el comunismo a nivel internacional será "la 'lucha por la paz' (...), la resistencia a los planes de expansión y dominación imperialista en todos los terrenos y, particularmente, en los grandes países occidentales, la defensa de la independencia nacional y la soberanía de cada país". A su vez, esa "defensa de la soberanía nacional frente a los embates del imperialismo norteamericano" que se impuso como tarea el PC tuvo sus repercusiones culturales en la "organización de un discurso que, mediante la condena al 'cosmopolitismo', pretendió defender y revalorizar las 'culturas nacionales' (...)" 5

La doctrina codificada por Zhdanov se constituye, así, como una respuesta cultural al programa de la lucha antiimperialista y por la defensa de la paz que pautaban los programas de acción del Partido Comunista para combatir al "imperialismo antidemocrático norteamericano", traducido en términos culturales, como "cosmopolitismo". En esta

\footnotetext{
${ }^{2}$ Solomon Volkov, El coro mágico. Una historia de la cultura rusa de Tolstói a Solzhenitsyn, Barcelona, Ariel, 2010, 179-190.

${ }^{3}$ Eric Hobsbawm, Historia del siglo XX, Buenos Aires, Crítica, 2010, 230.

${ }^{4}$ Entre 1945 y 1948, el Comité Central del Partido condena, por antisoviéticas, las obras de varias personalidades del mundo de la cultura y del arte, entre ellas, la segunda parte de Iván el terrible del cineasta Serguéi Eisenstein, las composiciones musicales de Shostakóvich y Prokofiev, los poemas de Anna Ajmátova y las narraciones satíricas de Mijail Zoschenko. Tal como afirma Horacio Crespo, a partir de esos años el realismo socialista alcanzó "un valor paradigmático incontestable, y se estableció como tal despóticamente, sin ningún atisbo posible de impugnación (...)”. Horacio Crespo, "Poética, política, ruptura", Cella, Susana (directora del volumen), La irrupción de la crítica, vol. X, Jitrik, Noé (dir.), Historia crítica de la literatura argentina, Buenos Aires, Emecé, 1999, 424.

${ }^{5}$ Adriana Petra, Intelectuales comunistas en la Argentina (1945-1963), Tesis de posgrado, Universidad Nacional de La Plata, Facultad de Humanidades y Ciencias de la Educación, en Memoria Académica, 2013, 184-185-215.
} 
dirección, los principios de la doctrina zdhanovista implicaron un virulento combate contra todas las manifestaciones "cosmopolitas" de la literatura y del arte -entre las que se incluía también a las "vanguardias", condenadas bajo el calificativo de "decadentes", "formalistas" y "deshumanizadas"- y la defensa de las tradiciones culturales nacionales. En efecto, en su famosa conferencia de 1945 ante la asamblea de escritores de Leningrado, que será ampliamente difundida en los órganos de prensa partidaria a nivel mundial, Zhdanov señalaba que la tarea que correspondía al estado soviético frente a la ofensiva imperialista iniciada tras el fin de la guerra, era doble: por un lado, "fustigar y atacar con audacia a la cultura burguesa" y, por otro, "restaurar" e "impulsar" "las más gloriosas tradiciones". ${ }^{6} \mathrm{El}$ ataque violento hacia la literatura "decadente" que se pone en juego en el discurso de Zhdanov y el llamado a restaurar las tradiciones serán la base doctrinaria sobre la que se asentará el acérrimo control sobre la producción cultural a lo largo de los años que van desde la posguerra hasta, por lo menos, los años posteriores a la muerte de Stalin.

Ahora bien, la imposición de la doctrina zhdanovista significó una nueva etapa en la implementación del realismo socialista también a escala internacional. Si hasta los años finales de la Segunda Guerra, en el marco de las políticas frentistas, el resto de los partidos comunistas del mundo no les exigió a sus intelectuales que extendieran su compromiso con las reivindicaciones partidarias al ámbito de la creación artística, la situación se modificó después de 1945, cuando, de acuerdo a Petra, se inicie una búsqueda por "profesionalizar" la participación de los intelectuales ligados al comunismo. Así, a "la concepción clásica que concebía la acción común de los intelectuales en función de una intervención puramente política avalada por su capital simbólico" se la reemplazó, señala Petra, por "una concepción profesionalista en la que el intelectual debía comprometer su obra o sus prácticas y competencias profesionales". Esta nueva concepción profesionalista supuso un cambio tanto en lo que concierne a la tarea y el rol específico que debían cumplir los intelectuales como a sus formas de organización, ahora centradas en la constitución de frentes por especialidad. ${ }^{7}$

No obstante estas consideraciones generales sobre la recepción internacional del zhdanovismo, en el ámbito local esa "exigencia profesionalista" se inflexiona de modo singular en relación con el contexto político nacional, signado por el fenómeno peronista. Como sostiene Petra, a pesar de la sobrevida que el peronismo impuso al frente intelectual antifascista, lo cierto es que los "vaivenes" que el PCA experimentó en la caracterización del peronismo "resultaron letales" para su permanencia en la comunidad intelectual antiperonista. En esta dirección, la búsqueda de unidad con el peronismo que, en 1952, bajo la dirección de Juan José Real, promovió el partido originó una radical redefinición tanto de la política de alianzas como de "los términos que gobernaban las interpretaciones comunistas sobre el pasado y las tradiciones ideológicas locales". En ese marco, los

\footnotetext{
${ }^{6}$ Andréi Zhdanov, "El frente ideológico y la literatura", en Máximo Gorki y Andréi Zhdanov, Literatura, filosofía y marxismo, México D.F., Grijalbo, 1968, 92-96. La conferencia de Zhdanov se inscribe en el marco de la censura que el partido infringe a dos revistas de Leningrado, por considerar que la publicación en ellas de textos de Zoshchenko y poemas de Ajmátova, constituyen un "grueso error político".

${ }^{7}$ Petra, op. cit., 109-110.
} 
intelectuales comunistas abandonarán "las instituciones culturales que hasta entonces integraban e incluso dirigían (como la SADE y el CLES), provocando el primer gran quiere del 'campo democrático' de la intelectualidad argentina". Estas redefiniciones tuvieron, según la autora, dos consecuencias. Por un lado, el alejamiento del amplio campo antiperonista hizo posible que el espacio cultural comunista adoptara "un perfil más definido en términos ideológicos e institucionales" y, por otro, "fortaleció la pretensión de autarquía que desde siempre tuvo el partido respecto a la cultura". 8

Pero, además, el creciente interés por la cultura nacional que comienzan a mostrar los comunistas argentinos por esos años no se explica solo por la adhesión al patriotismo zhdanovista sino por la combustión que genera la combinación de ese patriotismo con los problemas que suscita la política cultural del peronismo, cuyo exitoso "sistema de representaciones sobre lo nacional", de fuerte impronta nacionalista, abrevaba en las fuentes del hispanismo, el nativismo y el folclore. En esta dirección, siguiendo a Petra, el sistema de representaciones que promovía el peronismo, y que colisionaba con el panteón liberal que el comunismo había adoptado como propio desde su adhesión, en los años 30 al proyecto de la Generación del 37, movilizó a los intelectuales del partido a una relectura de las tradiciones. ${ }^{9}$

Podrían reconocerse dos momentos diferentes en la recepción de la doctrina zhdanovista en Argentina. Si en el primero, la dirigencia del PC argentino inició una álgida "purga antivanguardista" 10 que culminó, en 1948, con la expulsión del partido de Cayetano Córdova Iturburu; en un segundo momento, que puede situarse hacia 1950, con la creación de Cuadernos de Cultura -y, fundamentalmente, a partir de su séptima entrega, de julio de 1952, cuando Héctor Agosti asume su dirección- los intelectuales, escritores y poetas comunistas se embarcarán en la tarea -no exenta de tensiones, polémicas y discusiones- de ensayar modos de adaptación de los principios pautados por la doctrina soviética en la construcción de un programa literario de carácter nacional desde el cual pensar la literatura actual y pautar un camino a seguir para los escritores del partido.

Comencemos por revisar sucintamente ese primer momento, en el cual se suscitaron intensos debates y controversias en torno al rumbo que debían tomar los escritores comunistas ante las nuevas directivas soviéticas y que se concentraron fundamentalmente en el problema de las "vanguardias" y el "formalismo" artístico. En el marco de esas discusiones, el partido convoca en 1948 a una reunión plenaria de intelectuales comunistas, que será el inicio de una polémica entre Rodolfo Ghioldi y Cayetano Córdova Iturburu, cuyo final estará signado por la expulsión del segundo de las filas partidarias. En esa reunión se enfrentaron, tal como muestran Ana Longoni y Horacio Tarcus, dos posiciones: por un lado, la oficial, "sostenida en primer término por Rodolfo Ghioldi”, que promovía "la necesidad de adoptar un canon estético realista único para la creación cultural de los

\footnotetext{
${ }^{8}$ Ibid., 106-107.

${ }^{9}$ Ibid., 240.

10 Ana Longoni, Horacio Tarcus, "Pugna antivanguardista. Crónica de la expulsión de Córdova Iturburu del Partido Comunista", Ramona $\mathrm{n}^{\circ}$ 14, 2001, 55-57.
} 
artistas comunistas", y, por otro, la representada por Córdova Iturburu, "de mayor apertura a la vanguardia y a la libertad en la creación". Según señalan los autores, la posición sostenida por Iturburu era compartida por un buen número de artistas y escritores que, al igual que éste, "se resistió a la embestida que acusaba a las formas modernistas de propagar 'el irracionalismo, el antihumanismo, la reacción". Las discusiones que se produjeron entre ambos en esa reunión continuaron luego por correspondencia privada. Mientras Ghioldi, en esas cartas cruzadas, sostenía la necesidad, y la obligación, de rechazar cualquier influencia del modernismo en el arte, mientras que Córdova Iturburu, por su parte, afirmaba que "no es posible un arte revolucionario, nuestro, comunista, sin la utilización de los elementos estéticos y técnicos proporcionados por la gran experiencia artística y literaria de nuestra época". "Mi concepción del arte político de nuestro tiempo", dice el autor, "no es sino ésta: un contenido revolucionario expresado con el idioma de nuestros días". ${ }^{11}$ Los argumentos esgrimidos por Ghioldi para justificar su postura de rechazo a la vanguardia se centraban en la idea de que, lejos de tratarse de una mera cuestión referente a la "búsqueda de medios expresivos", el problema radicaría en la concepción del arte que los movimientos de vanguardia "traducen y postulan". Y, en este sentido, para Ghioldi "nadie puede negar que el rasgo característico del modernismo es la deshumanización del arte, con toda la carga irracionalista y desesperada que ello comporta necesariamente", lo que fundamentaría que sea inadmisible para el arte que pretenda representar los intereses del partido. A la autonomía del arte que demandaba Córdova Iturburu, Ghioldi le opone -avalando su postura con la cita del famoso texto de Lenin, "La organización del partido y la literatura del partido"- la idea de que si es evidente que existe una libertad inalienable, en tanto "el creador pone lo suyo, lo propiamente suyo", el partido no puede de ningún modo "admitir que en nombre de la 'libertad' se propague el irracionalismo, el antihumanismo, la reacción". 12

La polémica culmina, como adelanté, con la expulsión de Córdova de las filas partidarias. Y, aunque, según constata Petra, ${ }^{13}$ las comunicaciones oficiales del partido atribuyeron el hecho a la falta de compromiso con la militancia, lo cierto es que, cualquiera fuese su actuación concreta como militante, sus disidencias con las políticas culturales dogmáticas asestaron el tiro de gracia para su rápida desvinculación del partido.

Por su parte, la revista Cuadernos de Cultura marca un segundo momento de la recepción del zhdanovismo, más positivo que el anterior, aunque ese calificativo no es del todo exacto ya que, lejos de la unanimidad que parece indicar, la revista fue el escenario de múltiples polémicas y debates entre posiciones que, en ocasiones, fueron irreconciliables. Con su uso

\footnotetext{
${ }^{11}$ Ibid., 55, 57.

12 Ibid., 56. Según declaraba Lenin en ese artículo de 1905, la literatura debía "transformarse en literatura del partido", "en una parte de la causa general del proletariado, 'una pequeña rueda y un pequeño tornillo' en el gran mecanismo socialdemócrata, uno e indivisible, puesto en movimiento por toda la vanguardia consciente de toda la clase obrera". Esta subordinación de la literatura al partido supone que "el proletariado socialista organizado debe vigilar toda esta actividad, controlarla a fondo, introducir en ella el espíritu vivo de la causa viva del proletariado", pero asegurando, en cambio, "un buen lugar a la iniciativa personal, a las inclinaciones individuales, al pensamiento y a la imaginación, a la forma y al contenido" (87). Vladimir Lenin, Josef Stalin, Sobre la literatura y el arte, Buenos Aires, Problemas, 1942, 86-87-126.

${ }^{13}$ Petra, op. cit., 140.
} 
pretendo mostrar más bien que esos debates y polémicas funcionan en el marco de un proyecto compartido que busca adaptar los principios soviéticos en vistas de pensar la cultura en términos nacionales. Como señala Jorge Cernadas, Cuadernos mantuvo "vínculos de autonomía relativa pero también de tensión, y eventualmente de subordinación, con el 'núcleo duro' de la dirección política partidaria". ${ }^{14}$ Esa relativa autonomía hizo posible una apertura del espacio de la revista a diferentes perspectivas de análisis, en muchos casos distantes de las posiciones dogmáticas de la dirigencia. En líneas generales, podrían dilucidarse al menos dos posiciones diferentes en el interior de la revista: una, cuyo portavoz más cabal sería el joven Roberto Salama, fuertemente ligada a las posiciones ortodoxas del partido, y otra, abierta a una lectura más flexible de los dogmas, en la que Agosti desempeña un rol ciertamente fundamental.

La primera época de la revista Cuadernos cuenta con 84 números, publicados con cierta regularidad entre agosto de 1950 y marzo-abril de 1967, y tuvo entre sus colaboradores más frecuentes a los escritores y críticos literarios más relevantes del partido, entre ellos, Héctor Agosti, Raúl Larra, Roberto Salama, Raúl González Tuñón, José Portogalo, Amaro Villanueva, Álvaro Yunque, Carlos Ruiz Daudet, Juan José Manauta; elenco al que, al promediar los años cincuenta, se suman varios jóvenes intelectuales, escritores y críticos literarios, como Andrés Rivera, Juan Gelman, Marcelo Ravoni, José Luis Mangieri y Juan Carlos Portantiero, que a mediados de la década siguiente romperán abiertamente o serán expulsados del PC por sus disidencias con las líneas culturales y políticas ortodoxas que continuaba sosteniendo la dirigencia.

En sus primeros seis números, tal como sostiene Tarcus, la revista se propuso meramente como un espacio de propaganda y divulgación de documentos, ensayos y textos literarios ligados a la línea soviética; pero, a partir de su séptima entrega, cuando Héctor Agosti asume la dirección, comenzará a ampliar "el horizonte de su cultura marxista al tiempo que le otorgó un lugar central al debate cultural argentino". ${ }^{15}$ Así, la política de traducciones de Cuadernos se abre, sin dejar de lado las soviéticas, al campo de la crítica marxista francesa $\mathrm{y}$, fundamentalmente, italiana y comienza a incluir una serie de nuevas secciones, como "Los libros"; "Notas sobre cine"; "De cada cual lo suyo", donde se informa de las polémicas y novedades que tuvieron lugar en otras revistas o periódicos nacionales y extranjeros; "Crónica del tiempo", destinada a comentar diversos acontecimientos culturales de actualidad; "Cartas de lectores", de aparición más esporádica, que se propone como espacio de intercambio con el público; y "Polémicas", quizás la apuesta más fuerte en la medida en que da lugar al disenso como ocasión necesaria para el plan de convertir a la revista en un "órgano de estudio y discusión". La aparición de esas nuevas secciones, lo mismo que la ampliación del campo de las traducciones, evidencia un interés de intervención más amplio que la mera propaganda, vinculado a la posibilidad de echar mano

\footnotetext{
14 Jorge Cernadas, "La 'vieja izquierda' en la encrucijada: Cuadernos de Cultura y la política cultural del Partido Comunista argentino (1955-1963)", X Jornadas Interescuelas/Departamentos de Historia, Escuela de Historia, Facultad de Humanidades y Artes, UNR, Departamento de Historia de la Facultad de Ciencias de la Educación, UNL, s/p.

${ }^{15}$ Horacio Tarcus, "El corpus marxista", en Cella, Susana (directora del volumen), La irrupción de la crítica, vol X, Jitrik, Noé (dir.), Historia crítica de la literatura argentina, Buenos Aires, Emecé, 1999, 468.
} 
de los referentes teóricos marxistas para encontrar cauces de indagación que permitan dar cuenta de los problemas culturales nacionales. En este sentido, el zhdanovismo se conjugó con las primeras lecturas de la obra de Antonio Gramsci y de otros críticos y teóricos literarios como Mario De Micheli o Galvano della Volpe, propiciadas por Agosti. Sin embargo, esa apertura de la cultura marxista conocerá un límite preciso: la no discusión de los aspectos fundamentales que constituyen la base del marxismo-leninismo. En efecto, cuando los jóvenes intelectuales comunistas que rodean a Agosti comiencen a utilizar ese novedoso corpus textual marxista -fundamentalmente a Gramsci- para cuestionar las bases doctrinarias soviéticas, se iniciará un proceso de ruptura que culminará -como en 1948, con Córdova Iturburu - con la expulsión de los jóvenes de las filas partidarias. Así, como señala Tarcus, "el intento de apertura quedará a medio camino, pues los jóvenes a los que Agosti convoca para la tarea (...) llevan el gramscismo más lejos de lo que lo vislumbró Agosti y de lo que podía tolerar el partido, lo que desemboca en una álgida discusión" que precipita la salida de los jóvenes del PC. ${ }^{16}$

\section{El programa literario de Cuadernos de Cultura}

En lo que respecta específicamente al ámbito literario, tanto el entramado de las polémicas y las discusiones que se suscitan en las páginas de la revista, como la selección de los materiales que se traducen y difunden y la valoración de los libros reseñados ponen en juego una búsqueda por construir un programa literario que, adaptando la normativa del realismo socialista a un contexto signado por la agenda de problemas impuesta por el peronismo, regule las prácticas críticas y creativas nacionales. Cuadernos de Cultura se presenta, así, como un laboratorio en el que se ensayan y discuten diversas propuestas, que se tensionan de modo diferente con las posiciones de la dirigencia partidaria, en vistas de la elaboración de un aparato teórico-crítico capaz de orientar tanto las perspectivas de análisis y valoración de la literatura como el mismo trabajo de escritura literaria.

Ahora bien, es importante señalar que, más allá de la diversidad de perspectivas posibles y de las múltiples cercanías o distancias que cada propuesta individual entable con las líneas de fuerza partidarias, lo cierto es que todas comparten una base incuestionable: la del realismo, entendido, desde la teoría leninista del reflejo, como una "forma peculiar de conocimiento de la realidad" necesaria a los fines de su transformación, tal como postula Manauta en su ensayo crítico sobre la poesía de Pablo Neruda. ${ }^{17}$ Así entendido, el realismo supone que el artista debe no sólo reflejar la realidad en sus obras, de manera diferenciada

\footnotetext{
16 Ibid., 469.

${ }^{17}$ Juan José Manauta, “'Canto General': culminación del tema del hombre en la poesía de Pablo Neruda”, Cuadernos de Cultura $n^{\circ}$ 8, octubre 1952, 48. Tal como señala Crespo a propósito de la traducción del artículo de Parsadanov, "La lucha por el realismo en el arte", publicada en el número 15 de la revista, la teoría del reflejo que Lenin desarrolla en Materialismo y empiriocriticismo supone que la operación de conocimiento es la del reflejo del mundo, que existe independientemente de la conciencia del hombre, en la mente humana. Así, dice Crespo, "el sentido del arte y la literatura (...) es que refleje fielmente la realidad objetiva del mundo (...)" a partir de un medio propio, la imagen artística. Dichas imágenes posibilitarían que el artista refleje la realidad y, al mismo tiempo, influya sobre ella a los fines de su transformación. Crespo, op. cit., 426.
} 
de la mera copia de la superficie de los fenómenos, sino también contribuir a la modificación futura de esa misma realidad. En otras palabras, ese "reflejo" literario constituye una herramienta al servicio del cambio social. De este modo, el programa literario de la revista se sustenta en un sistema axiológico que identifica el valor de la literatura con su carácter instrumental, es decir, al servicio del principio pedagógico y moralizante que Máximo Gorki, en su discurso al Primer Congreso de Escritores Soviéticos, de 1934, definía como el deber del escritor de "despertar la responsabilidad colectiva". ${ }^{18}$

En función de este carácter instrumental asignado a la literatura, desde las páginas de Cuadernos se proyecta una idea de la literatura que pone en el centro del debate dos problemas que atañen a las resoluciones artísticas de las obras. Por un lado, el "elemento revolucionario" o la "salida" -lo que el realismo socialista definía como "el optimismo histórico"- y, por otro, la "comunicabilidad" de la literatura, dos cuestiones que remiten, en última instancia, al problema del contenido y la forma apropiadas que deben revestir las obras literarias realistas, tanto narrativas como poéticas, para cumplir con la misión de orientar al lector en su lucha.

En primer lugar, podría decirse que esa cualidad "comunicable" alude a un uso particular de la lengua que involucra la "virtud" del escritor para lograr, tal como sostiene Manauta, una "identificación fraternal" con el pueblo. ${ }^{19}$ Esta cuestión, relativa fundamentalmente a la forma de las obras, que se impone de manera sobresaliente como problema crítico en las reseñas y notas sobre literatura de la revista, aparece en general asociada a una explícita crítica al simbolismo, la literatura "pura" y la experimentación vanguardista. Así aparece formulado el problema en la reseña crítica de la antología poética Guatemala (1954), del grupo Poesía Buenos Aires, que escribe Juan Hidalgo para el número 21 de la revista, en donde rescata el interés por intervenir ante los episodios imperialistas sucedidos en Guatemala por parte un grupo que, hasta el momento, se había enfrentado al "problema poético, con una postura cerradamente individualista". En este sentido, señala que "una poesía (...) con una temática de definida orientación social, no puede perder su comunicabilidad (que es su esencia más entrañable) en los repliegues de un simbolismo más apto para crear ciertos torturados estados de ánimo que los sacrificios de un pueblo en lucha por su libertad". 20

Por su parte, las discusiones en torno al "elemento revolucionario"-que remite al problema de los "contenidos" de las obras y, en última instancia, a la representación realistaconforman un núcleo problemático en el que resuenan los ecos de los principios pautados por la doctrina soviética. En su discurso al Primer Congreso de Escritores Soviéticos, Gorki

\footnotetext{
18 Dice Gorki: "Los miembros del Partido que actúen dentro del dominio de la literatura deberán ser no solamente maestros de ideología revolucionaria que organizan las energías del proletariado en todos los países del orbe, sino que den muestras de fuerza moral y de verdadera disciplina. Esta fuerza deberá tender, ante todo, a despertar la responsabilidad colectiva". Máximo Gorki, "Discurso en el Primer Congreso de Escritores Soviéticos (1934)", Máximo Gorki, Andréi Zhdanov, op. cit., 54.

${ }^{19}$ Manauta, op. cit., 16.

${ }^{20}$ Juan Hidalgo, “Guatemala”, Cuadernos de Cultura n² 21, mayo de 1955, 120-121, 122.
} 
señalaba que la literatura popular de raigambre materialista, que el realismo socialista recoge como herencia, logra fundir "razón e intuición", entendiendo por "intuición" la capacidad de vislumbrar en el presente el triunfo final de los oprimidos sobre las clases que los oprimen. Y, gracias a esta conjunción, capta "la acción gestadora de la realidad", es decir, la dialéctica que anuncia el avance de las fuerzas motoras de la historia hacia la revolución proletaria y, después, hacia la sociedad sin clases, motivo por el cual "desconoce por completo el pesimismo". ${ }^{21} \mathrm{Si}$ la dialéctica materialista enseña que todo momento histórico contiene en sí las contradicciones cuyo desenvolvimiento será superado en una instancia posterior, de síntesis, el "reflejo" artístico tendría como objetivo captar esas contradicciones y mostrar su desenvolvimiento futuro. El realismo socialista, en sus vínculos con la invención, recupera una "actitud romántica" propia del mito y de la literatura popular que consiste en inyectar a la imagen extraída del dato de la realidad, su "posibilidad" de devenir real él mismo, es decir, su potencial revolucionario:

El mito es ficción, invento. Inventar es sacar de una suma de datos reales el sentido fundamental dándole forma a la imagen: así se hace realismo. Pero si a ese sentido del dato real se agrega, mediante el impulso de la idea conforme a la lógica del deseo, la posibilidad, redondeando así la imagen, se obtendrá el romanticismo que residía en el fondo del mito; impulso útil, puesto que ayuda a sugerir el vínculo revolucionario que une el deseo a la realidad; vínculo que en la práctica viene a transformar el mundo. ${ }^{22}$

Para Gorki, entonces, ese "elemento romántico" que reside en el fondo de todo mito expresa el vínculo entre realidad y deseo -o la realidad vista desde la perspectiva que ofrece la dialéctica de la historia- y, por lo mismo, es el elemento que posibilita a la literatura intervenir en la transformación del mundo.

En diálogo con esta concepción del realismo, el programa literario que se va definiendo desde Cuadernos enfrenta una dificultad ciertamente compleja: ¿cómo lograr una representación "optimista" de un país que enfrenta la amenaza del imperialismo y que aún se encuentra sometido a la explotación del sistema capitalista?, ¿cómo tiene que operar el escritor para captar, en ese presente tan poco alentador, las fuerzas que anticipen el triunfo final de los oprimidos? En esta dirección, podría decirse que tanto de las reseñas como de los artículos críticos y ensayos que se publican en la revista -más allá de las diferencias, en algunos casos sustanciales, en los puntos de vista de sus autores- se desprende un sistema de valoración que pone el acento afirmativo en la construcción de tramas narrativas capaces de representar los padecimientos de los trabajadores en las circunstancias de explotación a las que se encuentran sometidos, para derivar, en su desarrollo argumental, en una visión del triunfo que están llamados a cumplir, revistiendo así a la historia narrada de un carácter “ejemplar". No sólo los críticos más doctrinarios, como Salama, evidencian una clara preferencia hacia las obras literarias que manifiestan una mirada optimista acerca del futuro, por el contrario incluso los jóvenes que serán expulsados del partido en los años

${ }^{21}$ Gorki, op. cit., 23.

22 Ibid., 33. 
siguientes, mantienen esta perspectiva de análisis enfocada en el "elemento revolucionario". Así, por ejemplo, en su reseña sobre Campo arado, una novela de Ernesto Castro, Hugo Gola destaca que al autor se le escapó "cierto fermento rebelde difundido en el campo, cierto burbujeo de la realidad que está haciéndose pero donde obran ya las nuevas líneas del futuro desarrollo". ${ }^{23}$ También Portantiero en su reseña de la novela Mamita Yunai, de Carlos Luis Fallas, señala como uno de sus aciertos el descubrimiento del "proceso nacional" que explica "las causas reales de la miseria (...) y la posibilidad de superarla", aunque deplora que "el camino que lleva al personaje principal a defender el derecho de sus hermanos (...) no quede anotado con precisión". ${ }^{24}$

La polémica que tuvo lugar a comienzos del año 1954 en las páginas de la revista en torno al film Ladrones de bicicleta, de Vittorio de Sica, permite echar luz acerca del modo de funcionamiento de la idea del optimismo histórico o de la salida, en tanto aparato crítico de análisis literario. En la sección "Notas sobre cine", del número 14 de la revista, Alberto Foradori, el autor de los cuentos que resultarán galardonados con el primer premio del concurso a finales de ese mismo año, publica una dura crítica, en la que afirma que el film refleja una "lucha solitaria", según la lógica de que "el hombre es lobo del hombre", que apartaría "todo compromiso de participación activa, en un sentido crítico y no meramente documental". ${ }^{25}$ Podría decirse, así, que los argumentos esgrimidos por Foradori se sustentan en la ausencia en el desarrollo argumental de la película de una visión revolucionaria, en otras palabras, en el hecho de que las vicisitudes del personaje principal y su hijo no se resuelvan en una lucha comunitaria en pos del cambio social.

Dos números después, la revista publica, en la sección “Cartas del lector”, el comentario de un lector rosarino, Santiago Sivalov, quien toma un camino crítico que contradice la posición sostenida por Foradori. Sivalov señala que el film de De Sica es el "producto de un pueblo" que ha luchado para liberarse de la dictadura y que, si bien "ha ganado el derecho de hablar y ha aprendido a defender ese derecho", no ve todavía con claridad, en 1948, "cuál es el camino que deberá tomar para seguir su marcha hacia la redención total". ${ }^{26}$ Así, a la crítica de Foradori, que deplora la ausencia del "elemento revolucionario", el lector le opone un argumento focalizado en el problema del reflejo, de tal modo que, manteniéndose fiel a la realidad del momento histórico que el film representa, el conflicto del protagonista no podría resolverse aún por la vía de la "participación activa", como pedía Foradori.

Por su parte, en el número siguiente, de agosto de 1954, Roberto Raschella cierra el debate con un artículo titulado "Vittorio de Sica". Apoyando la línea argumentativa de Foradori, Raschella entiende que el film "quita" los rasgos característicos del proletariado contemporáneo, resuelto y revolucionario" y que, por ende, el espectador "se retira de la sala con el sabor amargo de la duda y el qué será”. En esta dirección, Raschella sostiene

\footnotetext{
${ }^{23}$ Hugo Gola, "Ernesto Castro. Campo arado", Cuadernos de Cultura n 14, enero de 1954, 121.

${ }^{24}$ Juan Carlos Portantiero, "Carlos Luis Fallas. Mamita Yunai", Cuadernos de Cultura n ${ }^{\circ}$ 24, marzo de 1956, 138.

${ }^{25}$ Alberto Foradori, "Ladrones de bicicleta”, Cuadernos de Cultura n 14, enero 1954, 102 - 104.

${ }^{26}$ Santiago Sivalov, "En torno a Ladrones de bicicleta", Cuadernos de Cultura n 16, enero 1954, 126-127.
} 
que De Sica debe "comprender que ante todo existe el pueblo, frente al cual su hipersensibilidad al dolor humano puede y debe evolucionar hacia un optimismo fundamentado". ${ }^{27}$ De manera singularmente clara, lo que reprocha Raschella de la estética cinematográfica de De Sica es, precisamente, que los conflictos no se resuelvan en una mirada optimista del futuro, en función de un espectador al que es necesario orientar e incentivar a la lucha. El film carecería, desde esta perspectiva, de una "salida", del "elemento revolucionario" que le muestre al público un camino de acción.

No obstante, Raúl González Tuñón sostenía un punto de vista diferente respecto del film, que había tenido oportunidad de ver en Moscú y cuyas apreciaciones comenta, muy sucintamente, en el diario de viaje que escribe a su regreso, Todos los hombres del mundo son hermanos, publicado el mismo año. Según Tuñón, la película "exhibe aberraciones del régimen capitalista, una desgarradora realidad de la Italia gobernada por los "democristianos"'. Y, si bien su desencadenamiento narrativo no ofrece una salida directa, "muestra un drama hondo, humano, que subleva", es decir, despierta la sensibilidad del público y lo predispone para luchar contra eso que lo indigna en la representación cinematográfica ${ }^{28} \mathrm{Al}$ igual que en el caso de Raschella y Foradori, la lectura de la "salida" efectuada por Tuñón apunta hacia afuera, es decir, hacia la reacción que se espera del público, pero la distancia entre ambas se produce en la apreciación en torno a si esa "salida" está presente o no en la obra de De Sica. Así, mientras para Raschella y Foradori, la construcción de los personajes y sus acciones no suscitan en el espectador más que duda y amargura, para Tuñón, en esa amargura se concentraría el principio de la transformación de la realidad. La sola denuncia bastaría, de acuerdo a Tuñón, para esclarecer la conciencia del público y guiarlo hacia la acción transformadora. No obstante, conviene recordar que Tuñón será uno de los jurados del concurso de cuentos organizado por Cuadernos, cuyos relatos ganadores, según veremos, presentan desenlaces se adecúan perfectamente a ese "optimismo" que pedía la doctrina soviética. Podría decirse, entonces, que si para Tuñón esa "salida" no necesariamente tiene que exponerse en el devenir argumental en el sentido de un "final feliz", continúa funcionando como valor a la hora de juzgar la calidad de las obras literarias.

Ese programa literario que se va desplegando en las intervenciones de Cuadernos busca intervenir en un doble frente: por un lado, en la lucha contra el "cosmopolitismo" artístico; por otro, en la construcción de una tradición literaria nacional y popular desde la cual pensar la historia de la literatura y de la cultura argentinas y, al mismo tiempo, las posibilidades de la literatura actual. En efecto, el programa literario definido en las páginas de la revista puede ser pensado como una estrategia en pugna y abierta confrontación con las manifestaciones "cosmopolitas" de la literatura argentina, entendidas como una "hipoteca de la soberanía cultural", ${ }^{29}$ es decir, como una derivación a nivel artístico y cultural de la amenaza que el imperialismo significa para la libertad política y económica

\footnotetext{
${ }^{27}$ Roberto Raschella, "Vittorio De Sica”, Cuadernos de Cultura n 17, agosto 1954, 64 -74.

${ }^{28}$ Raúl González Tuñón, Todos los hombres del mundo son hermanos, Buenos Aires, Poemas, 1954, 30.

${ }^{29}$ Así lo expresa Alberto Foradori en su "Balance crítico del cine argentino en 1952", publicado en el número 9/10 de la revista, de febrero de 1953, 121.
} 
de los pueblos. El horizonte más definido de este "cosmopolitismo", en el ámbito literario, no son sólo las prácticas vanguardistas, sino también el género policial, el fantástico, la novela existencialista y "psicologista", que se asocian a los nombres de Jorge Luis Borges, Adolfo Bioy Casares, Ernesto Sábato o Manuel Mujica Láinez, en un trazado de confrontaciones que culmina, por extensión, en Sur. En este sentido, por ejemplo, se expresa Julio Galer en su reseña a la novela de Beatriz Guido, La casa del Ángel. Allí, rescata la novela de Guido por su "realismo crítico", rótulo bajo el cual la crítica comunista designaba al peldaño previo al realismo socialista, frente a las obras de los "escritores de la burguesía", como las de Borges y Bioy que "optaron por la evasión lisa y llana", las de Mujica Láinez, quien "idealiza" los recuerdos del pasado, o Mallea, cuyo realismo "no va mucho más allá de la superficie" ${ }^{30}$ Asimismo, a propósito de su trasposición cinematográfica, la novela El Túnel, de Sábato, es calificada por Foradori, en su "Balance del cine" de 1952, como una "especie de versión vulgata de la mercadería existencialista" cuya condición vernácula se limita a unas pocas referencias a la ciudad de Buenos Aires. ${ }^{31}$ En el caso de Borges, la crítica también se dirige hacia las vetas criollistas de su literatura. Así, Villanueva señala que Borges, en tanto escritor de las "clases privilegiadas", aprovecha formalmente el "habla nacional" para sus fines exclusivos, totalmente opuestos a los verdaderos intereses del pueblo. ${ }^{32}$ En esta dirección, si bien Jorge Cernadas señala la "moderación parcial" de la crítica de Cuadernos a Sur ${ }^{33}$ lo cierto es que, centrando la mirada en los parámetros valorativos que sostienen el programa literario de la revista, se advierte que los mismos conducían necesariamente a una confrontación con los modelos literarios que promueve la revista de Ocampo, aunque esa confrontación no haya tomado salvo en algunos casos puntuales, como en el artículo de Tuñón, publicado en el número 4${ }^{34}$ los rasgos de un enfrentamiento explícito.

Ante esa literatura "cosmopolita" que, según afirmaba Zhdanov en su conferencia del 45, sólo puede "sembrar el desaliento", ${ }^{35}$ el programa de Cuadernos involucra diversas miradas retrospectivas de la literatura nacional en vistas de la construcción de una "herencia cultural" a partir de la cual consensuar y legitimar las modalidades de acercamiento de la literatura al mundo popular, a sus preocupaciones y problemáticas específicas; miradas retrospectivas que, progresivamente, siguiendo a Petra, van a ir trazando una genealogía comunista en tensión con el panteón liberal que el partido había adoptado como propio en

\footnotetext{
${ }^{30}$ Julio Galer, "Beatriz Guido. La casa del Ángel", Cuadernos de Cultura n 21, mayo de 1955, 120.

${ }^{31}$ Foradori, op. cit., 122.

32 Amaro Villanueva, "Un parecer", Cuadernos de Cultura n²4, marzo de 1956, 150.

${ }^{33}$ Cernadas, op. cit.

34 En ese artículo, titulado "El caso de Madame Victoria Ocampo", Tuñón critica el premio de honor que la SADE entregara a la directora de Sur. El autor hace un repaso por la trayectoria cultural de Ocampo y su revista intentando evaluar la pertinencia del premio y, si bien destaca algunos aportes "estimables" a la cultura y la publicación de algunos "libros valiosos, de rico contenido humano", señala que, a pesar de estos "aciertos" y de la "quizá buena intención al principio", la revista culminó por tipificarse "en el reaccionarismo congelado, el clan familiar, el círculo restringido, con pretensiones de 'haute culture' que se resuelve en 'haute couture', generalmente...y en alta cursilería". Pero, además, Tuñón denuncia a la directora de Sur por su "admiración al imperialismo yanqui" y su posición "extranjerizante ciento por ciento" y a la SADE por convertirse en un "simple centro recreativo aristocratizante". Raúl González Tuñón, "El caso de Madame Victoria Ocampo", Cuadernos de Cultura n 4, diciembre de 1951, 105.

${ }^{35}$ Zhdanov, op. cit., 76.
} 
los años 30, aunque sin llegar nunca a romper definitivamente con él. En los términos definidos por Agosti, "mirar hacia la herencia cultural, que es universal y nacional al mismo tiempo" supone "reconocer nacionalmente la línea de continuidad histórica de un pueblo". ${ }^{36}$ Estas nuevas orientaciones abarcan un amplio espectro que va desde la indagación del folclore, del habla popular o de la gauchesca -tal como se advierte en los artículos y ensayos de Villanueva, Ruiz Daudet, Agosti, Manauta o Yunque- hasta la recuperación para la tradición comunista de la obra de los escritores del 900, como Roberto Payró, Florencio Sánchez o Manuel Gálvez, la de Boedo, o, con mayor nivel de controversia, las de Roberto Arlt y Ricardo Güiraldes, alrededor de cuyas obras se suscitan intensas polémicas en las páginas de la revista. ${ }^{37}$ Sin embargo, más allá de la amplitud de líneas hereditarias en torno de las cuales los intelectuales comunistas ensayan en reseñas, comentarios y notas críticas la construcción de una tradición literaria propia, lo cierto es que, tal como lo muestran los cuentos ganadores del concurso literario que la revista publica en su número 19, las prácticas creativas de los escritores comunistas parecen encontrar el camino para la elaboración de un realismo de temática nacional en la herencia de Boedo.

\section{Las posibilidades del realismo en Argentina: el concurso de cuentos}

Volvamos a los cuentos ganadores del concurso organizado por la revista. En "El hombre de los zapatos amarillos", Vicente, un niño que trabaja como lustrabotas es maltratado por un adulto resentido y frustrado que no quiere pagarle por su trabajo y lo tilda de ladrón. Por su parte, "Un mañana cualquiera" narra un episodio de la vida de Emilio, un albañil, que se entera de que ha sido suspendido de su trabajo por una "orden de arriba", que muy probablemente esté relacionada, según nos enteramos por las tribulaciones del protagonista, con la pregunta que hace un tiempo le hizo al capataz de la obra por las botas de goma que tardaban en llegar. "Los Funes" relata las duras condiciones de vida de una familia de peones rurales que debe cumplir con los términos del contrato de arrendamiento y que ve frustradas sus esperanzas de un futuro mejor, condensadas en la promesa del "reparto de tierra" que le hicieran los "representantes de un nuevo partido político". Este dato no es menor, pues remite directamente al contexto del peronismo y, aunque en clave ficcional, viene a denunciar el incumplimiento de su plataforma de campaña respecto a la cuestión rural. Por último, en “¡Soñador, feliz soñador!”, Jacobo, un inmigrante judío -que ha sido amputado de una pierna luego de un accidente con el arado y que, a causa de la invalidez, se ve obligado a marcharse a la ciudad con su esposa y sus cinco hijos- se encuentra vendiendo cigarros en las calles casi desiertas de la ciudad, al fin de una lluviosa jornada de viernes.

\footnotetext{
${ }^{36}$ Héctor Agosti, "Los problemas de la cultura argentina y la posición ideológica de los intelectuales comunistas", Cuadernos de Cultura $\mathrm{n}^{\circ}$ 25, mayo 1956, 149.

37 Para un estudio pormenorizado de ambas polémicas, recomiendo: Petra, op. cit.; Julieta Núñez, Diego Poggiese, "Discusiones sobre el realismo literario en Cuadernos de Cultura", en María Celia Vázquez (coord.). Intervenciones intelectuales en el contexto del peronismo clásico, Bahía Blanca, Ediuns, 2011, 139-202; Alexia Massholder, El Partido Comunista y sus intelectuales. Pensamiento y acción de Héctor Agosti, Buenos Aires, Ediciones Luxemburg, 2014.
} 
En efecto, tal como afirmé más arriba, las tramas de los cuentos parecen indicar que las posibilidades de un realismo nacional estarían dadas por la herencia del miserabilismo boedista. Salvo por algunas referencias que los sitúan en los años del primer peronismo (como la del partido político que no cumple sus promesas en "Los Funes" o la referencia a los "cabecitas negras" en "Una mañana cualquiera" que aparece para mencionar a un niño que el protagonista se cruza en su caminata), los argumentos que acabo de presentar sucintamente bien podrían ser adjudicados a algunos de los principales escritores boedistas.

De acuerdo a Graciela Montaldo, aunque el programa ideológico y estético del grupo de Boedo no contó con una formulación explícita y una definición política clara, lo cierto es que replanteó la función y el valor de la literatura en términos eminentemente pedagógicos, es decir, como una práctica útil a la educación del pueblo. En tanto veristas, los escritores de Boedo buscaron producir, según la autora, una literatura capaz de "construir una verdad" que devele las mentiras del sistema capitalista. Así, "la MORAL del artista, la VERDAD del arte y la EDUCACIÓN del pueblo" serían los tres ejes en torno a los cuales se fue construyendo el movimiento cultural boedista. ${ }^{38}$ En los términos de Analía Capdevila, se trata de una literatura que apela a un "método de estudio" específico, basado en la experiencia directa, o en otras palabras, en la "compenetración" del escritor con "la vida del pueblo que sufre y trabaja". Ese mismo "pueblo que sufre y trabaja", como horizonte de lectores a los que apunta la literatura de Boedo, vendría a completar el proceso de la labor literaria a partir de la toma de conciencia acerca de "la injusticia social (...) que promueve algún tipo de resistencia frente al orden establecido".39 De esta manera, la literatura boedista se constituye como una denuncia social que busca poner a los lectores ante ficciones que, marcadas por un miserabilismo pesimista $-\mathrm{y}$, en muchos casos, por la más cruel desesperanza-, le muestren la explotación y la humillación a las que son sometidos por el injusto sistema y de la que son sus principales víctimas. ${ }^{40}$ En términos de Alejandro Eujanian y Alberto Giordano, más que propagandístico y partidario, el propósito del programa literario del grupo de Boedo, era pedagógico y moralizante: "menos convocar a la lucha política en una determinada dirección, que posibilitar la educación de los sujetos "embrutecidos". ${ }^{41} \mathrm{Y}$, en este sentido, el programa de Boedo se aleja críticamente de la literatura popular pintoresquista, que construye una mirada idealizada de la pobreza. Al contrario, la literatura de Boedo tiene a exacerbar las descripciones de las penurias y miserias de la clase para, lejos de complacer, ayudar a que el lector tome conciencia de su propia condición.

\footnotetext{
${ }^{38}$ Graciela Montaldo, "Literatura de izquierda: humanitarismo y pedagogía", en Graciela Montaldo (dir.) Yrigoyen, entre Borges y Arlt (1916-1930). Historia Social de la Literatura Argentina, Tomo VII, Buenos Aires, Paradiso, 2016, 327, 329; mayúsculas en el original.

39 Analía Capdevila, "Las aporías de la vanguardia", en Alle, María Fernanda (coord. e introd.), "Dossier. Literatura, cultura y pensamiento de izquierdas en la Argentina del siglo XX", Badebec n ${ }^{\circ}$ 9, 2015, 202-204.

${ }^{40}$ Oscar Blanco, "Modulaciones de un realismo (/naturalismo) militante. Direcciones invertidas, del naturalismo argentino a la literatura de Boedo", en Vitagliano, Miguel (comp.), Boedo. Políticas del realismo, Buenos Aires, Título, 2012, 1552.

41 Alejandro Eujanian, Alberto Giordano, "Las revistas de izquierda y la función de la literatura: enseñanza y propaganda”, Gramuglio, María Teresa (directora del volumen), El imperio realista, vol. 6, Jitrik, Noé (dir), Historia crítica de la literatura argentina, Buenos Aires, Emecé, 2002, 399.
} 
Ahora bien, si en los cuentos del concurso de Cuadernos los personajes, los ambientes en los que se mueven y sus conflictos remiten al miseriabilismo boedista, en tanto efectivamente exponen los signos de la pobreza, la injusticia social y política y el sistema de explotación al que están sometidos, lo cierto es que los desenlaces frustran esa adscripción. Contra las expectativas fundadas en las condiciones en las que se encuentran los personajes, que parecen conducir a un callejón sin salida, los cuatro cuentos tienen un final que, si bien no es estrictamente "feliz", deja entrever un futuro, ya fuera del cuento en sí, en el que los núcleos problemáticos podrían superarse. En "El hombre de los zapatos amarillos", Vicente no se deja doblegar por el maltrato del adulto resentido y se atreve a responderle que no es un ladrón, sino que está haciendo su trabajo. En "Una mañana cualquiera", Emilio llega a su humilde habitación de conventillo, le cuenta a su mujer de la suspensión y ella, lejos de desanimarse, le dice que se van "a arreglar" y le prepara el almuerzo. ${ }^{42}$ "Los Funes" culmina con una reunión de campesinos en la que cada uno se anima a hablar de sus problemas y comprenden, tal como piensa Amelia, la mujer, que "la lucha es la única salvación”. Por último, en "iSoñador, feliz soñador!”, Jacobo llega a la habitación que oficia de hogar, donde su familia lo recibe alegremente. Después de la cena, mientras sus hijos hacen la tarea de la escuela y su esposa se dedica a las labores de costura con las que colabora en la economía familiar, Jacobo comienza a imaginar el "brillante porvenir" que les espera a sus hijos y el orgullo que sentirá por ellos. ${ }^{43}$

A pesar de su muy cuestionable valor literario -y quizás también por esa misma razónestos cuentos exponen de manera simplificada y perspicaz - casi escolar, podría decirse- los parámetros de valoración que alimentan a la crítica partidaria. Los finales de esos cuentos, en los que el conflicto, aunque no se resuelve definitivamente, encuentra en la actitud de los personajes un potencial de resolución hacia un futuro más o menos próximo, develan modos posibles de pensar un realismo socialista nacional. Por un lado, entonces, los cuentos se hacen eco de ese deber de recuperación de las tradiciones nacionales populares, y realistas, alentado por el zhdanovismo, en la medida en que encuentran en la historia literaria argentina un antecedente, ajeno y hasta opuesto a la experiencia de la vanguardia, desde donde partir para oponer a la amenaza del cosmopolitismo cultural. La literatura de Boedo, así, ofrecía no solo una galería de personajes, circunstancias y conflictos que podían oficiar de trampolín para ensayar una literatura nacional acorde con los principios del realismo socialista, sino también un modelo del arte concebido en términos pedagógicos, como instancia capaz de propiciar un cambio en el lector. Por otro, las tramas narrativas de

\footnotetext{
${ }^{42}$ Es interesante destacar que en el cuento hay una referencia a la cinematografía italiana que puede ser leída en relación con la posición negativa acerca del film de De Sica que el autor había explicitado ese mismo año en las páginas de la revista. Hacia el final del relato, cuando el reciente desempleado, invadido por la preocupación, le cuenta a su mujer lo sucedido y ella, lejos de "desanimarse" y "ponerse a llorar" (tal como él imagina que sucederá), le sonríe y lo alienta, él recuerda que esa sonrisa es la misma con la que lo miraba cuando "después de haber ido al cine a ver una película italiana, le daba unas palmadas en las caderas". La referencia no es casual ni ingenua, al contrario, parece explicar esa preocupación que sobrevuela al personaje en su caminata desde el trabajo hasta su hogar, como una suerte de horizonte artístico que decide su estado anímico ante la injusticia de la suspensión. En este sentido, el desenlace del cuento, tanto como el apoyo que recibe de sus compañeros de trabajo, puede leerse como una corrección, un modo de enmendar ese "despojo de esperanza" y esa "falta de participación activa" que Foradori encuentra en el cine de De Sica.

43 "Los cuentos premiados", op. cit., 154, 158.
} 
los cuentos exploran posibles vías de incorporación de ese "elemento revolucionario" que pautaba el realismo socialista y del que carece la literatura de Boedo. Si la literatura del mundo sometido a la amenaza imperialista tiene que "reflejar" la realidad de un mundo dominado por la injusticia de la división de clases, los desenlaces de los cuentos encuentran el modo de fundir, en palabras de Gorki, "razón e intuición", es decir, de anunciar un futuro superador de las contradicciones del presente. En definitiva, entonces, "las posibilidades de una literatura realista en Argentina", de acuerdo a la óptica partidaria, y tal como ponen en evidencia estos cuentos, parece estar dada por la síntesis del miserabilismo boedista con ese "elemento revolucionario" que faltaba en Boedo.

En esta dirección, es posible definir las discusiones en torno a las elecciones de "contenido" y "forma" y, de manera consecuente, la delimitación del público lector que pone en juego ese programa, como un "boedismo optimista", en la medida en que recupera una mirada de la pobreza filiada con el miserabilismo de Boedo -aunque desviando sus alcances, de acuerdo a un nuevo contexto social signado por el peronismo, desde la representación del "lumpen" que, de acuerdo a la perspectiva crítica partidaria, caracteriza a Boedo, a la del obrero industrial, el peón y el arrendatario rural- ${ }^{44}$ para ponerla en función de ese "desarrollo revolucionario" que deben "reflejar" las obras comunistas. El programa de Cuadernos, entonces, viene a completar el de Boedo, dotándolo -siguiendo la argumentación de Andrés Rivera en su reseña a La cruz nuestra de cada día, de Roberto Mariani, aparecida en el número 23 de la revista- de "ese elemento revolucionario que canalice la angustia" del que aquel carecía. ${ }^{45}$

\section{Proyecciones. Hacia los años sesenta}

Para ir finalizando, me interesa destacar que el programa literario del comunismo en los años 50, tal como se difunde y se promueve desde las páginas de Cuadernos, constituye un momento central de las discusiones en torno a las estéticas realistas en Argentina que prácticamente no ha sido abordado por los estudios literarios. Así, a los dos momentos de "mayor intensidad" de las polémicas sobre el realismo señalados por María Teresa Gramuglio - aquel que se inicia con la contienda entre Boedo y Florida y culmina en los años 30 y aquel que tiene lugar en la década del 60-, este trabajo repone otro eslabón, situado entre ambos, que articula y conecta históricamente la serie. ${ }^{46}$ La reconstrucción de la dinámica de este momento intermedio, con su universo de problemas, tópicos, enfoques analíticos y paradigmas valorativos - pero también con una amplia producción literaria que

\footnotetext{
${ }^{44}$ Larra, por ejemplo, destaca "la necesidad de llevar a la literatura y al arte la cuestión social" como rasgo positivo de la literatura boedista, pero señala que su "defecto" radica en que "más que la clase obrera es el lumpen, el paria, quien está presente en su obra". Raúl Larra, "Roberto Arlt es nuestro", Cuadernos de Cultura n 6, febrero de 1952, 108.

${ }^{45}$ Andrés Rivera, "Fidelidad de los humildes", Cuadernos de Cultura ${ }^{\circ}$ 23, diciembre de 1955, 40.

${ }^{46}$ Gramuglio, María Teresa, "El realismo y sus destiempos en la literatura argentina", en Gramuglio, María Teresa (directora del volumen), El imperio realista, vol. 6, Jitrik, Noé (dir), Historia crítica de la literatura argentina, Buenos Aires, Emecé, 2002, 29.
} 
lo sostiene y que es necesario seguir explorando- ${ }^{47}$ permite proyectar nuevas vías de indagación sobre las líneas de continuidad y las rupturas que atraviesan esa serie histórica del realismo en Argentina.

En esta dirección, es preciso preguntarse por el impacto que el programa comunista de los años cincuenta pudo haber tenido en los nuevos proyectos realistas que se formulan y se discuten en los años sesenta. No es casual, siguiendo estas ideas, que, como ya señalé al inicio de este trabajo, la revista haya sido el espacio en el que, hacia mediados de la década del 50, comienzan a hacer sus primeras incursiones en la crítica literaria la mayoría de los jóvenes escritores y críticos -entre ellos, Andrés Rivera, Juan Gelman, Marcelo Ravoni, Carlos Brocato, José Luis Mangieri, Juan Carlos Portantiero- que en la década siguiente, ya fuera de la revista y del PC, favorecerán, desde sus propios medios de difusión, como las revistas Nueva Expresión, Pasado y Presente o La rosa blindada, diversas reformulaciones del realismo.

Aunque subrayando el carácter inicial -y, por ende netamente conjetural y provisorio- de esta hipótesis, podría decirse que los resultados de este trabajo abren un camino para repensar, por ejemplo, la importancia que Portantiero concede, en el libro que publica en 1961, Realismo y realidad en la narrativa argentina, al movimiento boedista, al afirmar que, a pesar de sus "limitaciones", "toda la literatura de izquierda en Argentina (es decir, todo el cuerpo vivo de la narrativa argentina) está marcada por su sello". ${ }^{48}$ Más concretamente, a la luz del análisis que he realizado en estas páginas, se vuelve necesario evaluar los alcances polémicos, pero también las cercanías analíticas y valorativas, que el ensayo de Portantiero tiene con el programa literario comunista de los 50. Así, es importante advertir, en las entrelineas de la argumentación que, si entre esas "limitaciones" del boedismo que Portantiero destaca, se encuentran sus "lastres anárquicos", unas páginas atrás el autor había señalado que la "visión anarquista es siempre una visión fatídica. Se vincula más a la desesperación posible del proletariado, que a la comprensión histórica de su poder como clase, en la medida en que adquiera autoconciencia, se organice y luche". ${ }^{9}$ Es decir que un núcleo problemático de la literatura de Boedo que es necesario superar estaría dado, para Portantiero, precisamente por la visión "fatídica" y "desesperada" de sus "lastres anárquicos". Cabría preguntarse, entonces, ¿qué líneas de continuidad pueden trazarse entre esa "comprensión histórica" que el joven Portantiero opone a la "visión anarquista" y el "boedismo optimista" que definía al programa literario del comunismo? Si ciertamente Portantiero rompe con su inmediato antecedente, entre otras razones, porque propone recuperar para el "verdadero realismo" los aportes expresivos de la vanguardia, ¿no hay también en sus planteos -y a pesar quizás de lo que él mismo hubiera pretendidoalgunas resonancias críticas, restos teóricos o huellas valorativas de esa síntesis del miserabilismo boedista con el elemento revolucionario que estaba en la base del realismo

\footnotetext{
${ }^{47}$ En efecto, escritores como Alfredo Varela, Manauta, Villanueva o González Tuñón producen, por esos años, una amplia gama de obras literarias, tanto poéticas como narrativas, que de uno u otro modo se hacen eco de los programas literarios del partido.

${ }^{48}$ Portantiero, Juan Carlos, Realismo y realidad en la narrativa argentina, Buenos Aires, Eudeba, 105.

${ }^{49}$ Ibid., 115-110; las cursivas son mías.
} 
tal como lo promovía la línea cultural partidaria? Dejo abiertas estas preguntas que serán, seguramente, materia de próximos estudios.

\section{Bibliografía consultada}

\section{Corpus}

Cuadernos de Cultura (Primera época), n²1, agosto de 1950; n84, marzo-abril de 1967.

Fuentes impresas

Altamirano, Carlos, Peronismo y cultura de izquierda, Buenos Aires, Temas, 2001.

--- Intelectuales. Notas de investigación sobre una tribu inquieta, Buenos Aires, Siglo XXI, 2013.

Blanco, Oscar, "Modulaciones de un realismo (/naturalismo) militante. Direcciones invertidas, del naturalismo argentino a la literatura de Boedo", en Vitagliano, Miguel (comp.), Boedo. Políticas del realismo, Buenos Aires, Título, 2012.

Bourdieu, Pierre, "Campo del poder, campo intelectual y habitus de clase". Intelectuales, política y poder, Buenos Aires, Eudeba, 1999, 23-41.

--- "Las condiciones sociales de la circulación internacional de las ideas", Intelectuales, política y poder, Buenos Aires, Eudeba, 1999, 23-41.

--- Las reglas del arte. Génesis y estructura del campo literario, Barcelona, Anagrama, 1995.

Camarero, Hernán. "La izquierda como objeto historiográfico. Un balance de los estudios sobre el socialismo y el comunismo en la Argentina". Nuevo Topo. Revista de historia y pensamiento crítico $\mathrm{n}^{\circ} 1,2005$.

Crespo, Horacio, "Poética, política, ruptura", Cella, Susana (directora del volumen), La irrupción de la crítica, vol. X, Jitrik, Noé (dir.), Historia crítica de la literatura argentina, Buenos Aires, Emecé, 1999.

Eujanian, Alejandro, Giordano, Alberto, "Las revistas de izquierda y la función de la literatura: enseñanza y propaganda", Gramuglio, María Teresa (dir. del vol.), El imperio realista, vol. 6, Jitrik, Noé (dir), Historia crítica de la literatura argentina, Buenos Aires, Emecé, 2002.

González Tuñón, Raúl, Todos los hombres del mundo son hermanos, Buenos Aires, Poemas, 1954.

Gramuglio, María Teresa, "El realismo y sus destiempos en la literatura argentina", en Gramuglio, María Teresa (directora del volumen), El imperio realista, vol. 6, Jitrik, Noé (dir), Historia crítica de la literatura argentina, Buenos Aires, Emecé, 2002.

--- "Prólogo", en Portantiero, Juan Carlos, Realismo y realidad en la narrativa argentina, Buenos Aires, Eudeba, 2011. 
Groys, Boris, La obra de arte total Stalin, Valencia, Pre-Textos, 2008.

Heller, Leonid, Baudin, Antoine, "Le réalisme socialiste comme organization du champ culturel". Cahiers du monde russe et soviétique vol. 34, n 3, 1993.

Hobsbawm, Eric, Historia del siglo XX, Buenos Aires, Crítica, 2010.

Gilbert, Isidoro. La Fede. Alistándose para la revolución. La Federación Juvenil Comunista 19212005. Buenos Aires: Sudamericana, 2009.

Gorki, Máximo, Zhdanov, Andréi Literatura, filosofía y marxismo, México D.F., Grijalbo, 1968.

Lenin, Vladimir, Stalin, Josef Stalin, Sobre la literatura y el arte, Buenos Aires, Problemas, 1942.

Massholder, Alexia, El Partido Comunista y sus intelectuales. Pensamiento y acción de Héctor Agosti, Buenos Aires, Ediciones Luxemburg, 2014.

Montaldo, Graciela, "Literatura de izquierda: humanitarismo y pedagogía", en Graciela Montaldo (dir.) Yrigoyen, entre Borges y Arlt (1916-1930). Historia Social de la Literatura Argentina, Tomo VII, Buenos Aires, Paradiso, 2016.

Núñez, Julieta, Poggiese, Diego, "Discusiones sobre el realismo literario en Cuadernos de Cultura", en María Celia Vázquez (coord.). Intervenciones intelectuales en el contexto del peronismo clásico, Bahía Blanca, Ediuns, 2011.

Pasolini, Ricardo, Los marxistas liberales. Antifascismo y cultura comunista en la Argentina del siglo XX, Buenos Aires, Sudamericana, 2013.

Portantiero, Juan Carlos, Realismo y realidad en la narrativa argentina, Buenos Aires, Eudeba, 2011.

Robin, Regine, Le réalisme socialiste. Une esthétique impossible. Paris: Payot, 1986.

Sapiro, Gisèle, "Le champ est-il national? La théorie de la différenciation sociale au prisme de l'histoire globale", Actes de la recherche en sciences sociales $\mathrm{n}^{\circ}$ 200, 2013.

--- "How Do Literary Works Cross Borders (or Not)? A Sociological Approach to World Literature", Journal of World Literature n $1,2016$.

Slonim, Marc. Escritores y problemas de la literatura soviética. 1917-1967, Madrid, Alianza Editorial, 1974.

Tarcus, Horacio, "El corpus marxista", en Cella, Susana (dir. del vol.), La irrupción de la crítica, vol X, Jitrik, Noé (dir.), Historia crítica de la literatura argentina, Buenos Aires, Emecé, 1999.

Terán, Oscar. Nuestros años sesentas. Buenos Aires: Puntosur, 1991.

Volkov, Solomon, El coro mágico. Una historia de la cultura rusa de Tolstói a Solzhenitsyn, Barcelona, Ariel, 2010. 
Fuentes digitales

Capdevila, Analía, "Las aporías de la vanguardia", en Alle, María Fernanda (coord. e introd.), "Dossier. Literatura, cultura y pensamiento de izquierdas en la Argentina del siglo XX", Badebec vol. $5, \mathrm{n}^{\circ} 9,2015$.

Cattaruzza, Alejandro. "Visiones del pasado y tradiciones nacionales en el Partido Comunista Argentino (ca. 1925-1950)". A contracorriente vol. 5, n 2, 2008.

--- "Las lecturas comunistas del pasado nacional en una coyuntura incierta (1955-1966). Herencias, ajustes y novedades", en Alle, María Fernanda (coord. e introd.). "Dossier: Literatura, cultura y pensamiento de izquierdas en la Argentina del siglo XX". Badebec vol. 5, n 9, 2015.

Cernadas, Jorge, "La 'vieja izquierda' en la encrucijada: Cuadernos de Cultura y la política cultural del Partido Comunista argentino (1955-1963)", X Jornadas Interescuelas/Departamentos de Historia, Escuela de Historia, Facultad de Humanidades y Artes, UNR, Departamento de Historia de la Facultad de Ciencias de la Educación, UNL.

Longoni, Ana, Tarcus, Horacio, "Pugna antivanguardista. Crónica de la expulsión de Córdova Iturburu del Partido Comunista", Ramona n 14, 2001.

Petra, Adriana, Intelectuales comunistas en la Argentina (1945-1963), Tesis de posgrado, Universidad Nacional de La Plata, Facultad de Humanidades y Ciencias de la Educación, en Memoria Académica, 2013. 